\author{
() И.Ю. Тиссен ${ }^{1}$, А.А. Лебедев ${ }^{1}$, Е.Р. Бычков ${ }^{1}$, Н.В. Лавров ${ }^{2}$, В.И. Морозов ${ }^{1}$, \\ П.Д. Шабанов ${ }^{1,3}$ \\ 1 ФГБНУ «Институт экспериментальной медицины», Санкт-Петербург; \\ ${ }^{2}$ ФГБОУ ВО «Санкт-Петербургский государственный педиатрический медицинский университет» Минздрава России, \\ Санкт-Петербург; \\ ${ }^{3}$ ФГБВОУ ВО «Военно-медицинская академия им. С.М. Кирова» Минобороны России, Санкт-Петербург
}

Для цитирования: Тиссен И.Ю., Лебедев А.А., Бычков Е.Р., и др. Орексины и подкрепляюшие системы мозга // Обзоры по клинической фармакологии и лекарственной терапии. - 2019. - Т. 17. - № 4. - С. 5-18. https://doi.org/10.7816/RCF1745-18

Поступила: 08.10.2019

Одобрена: 12.11 .2019

Принята: 18.12.2019

Целью обзора было проанализировать нейрохимические и нейрофизиологические механизмы орексиновой системы, ее роль в функциях организма и адаптивного поведения. Основное внимание уделено участию орексинов в механизме подкрепления и формировании аддиктивного поведения. В начале обзора дается историческая справка о первых работах в области изучения орексинов и идентификации рецепторов. Описаны орексинпродуцирующие клетки гипоталамуса и их влияние на функции мозга. Далее описано влияние орексинов и их рецепторов на пищевое поведение, уровень бодрствования и положительное подкрепление. Проанализировано действие орексинов при нарколепсии. Описано участие орексинов в механизмах подкрепления и зависимости, ключевая роль орексинов в развитии аддиктивных форм поведения. Показана особая роль орексина в формировании зависимости от этанола. Далее рассматривается вопрос о действии орексинов при стрессе. Показано, что орексины играют важную роль в регуляции нервных и гуморальных механизмов, опосредующих формирование эмоциональной памяти, ассоциированной с негативным опытом. Сделан вывод, что орексин может модулировать оценку стресса и вероятности достижения подкрепляющего стимула. В связи с этим антагонисты орексина могут рассматриваться как возможные перспективные средства профилактики и лечения расстройств тревожнофобического спектра, а также вызванных стрессом и окружающими стимулами среды расстройств, связанных с приемом аддиктивных средств.

Ключевые слова: орексины; рецепторы орексина; подкрепление; стресс; расширенная миндалина; нарколепсия.

\title{
OREXINS AND THE BRAIN REINFORCING SYSTEMS
}

\author{
(C) I.Yu. Tissen ${ }^{1}$, A.A. Lebedev ${ }^{1}$, E.R. Bychkov ${ }^{1}$, N.V. Lavrov², V.I. Morozov ${ }^{1}$, P.D. Shabanov ${ }^{1,3}$ \\ ${ }^{1}$ Institute of Experimental Medicine, Saint Petersburg, Russia; \\ ${ }^{2}$ St. Petersburg State Pediatric Medical University, Saint Petersburg, Russia; \\ ${ }^{3}$ S.M. Kirov Military Medical Academy, Saint Petersburg, Russia
}

For citation: Tissen IYu, Lebedev AA, Bychkov ER, et al. Orexins and the brain reinforcing systems. Reviews on Clinical Pharmacology and Drug Therapy. 2019;17(4):5-18. https://doi.org/10.17816/RCF1745-18

The purpose of the review was to analyze the neurochemical and neurophysiological mechanisms of the orexin system and the role of orexin in body functions and behavior. The focus is on the participation of orexin in the mechanisms of reinforcement and the formation of addictive behavior. At the beginning of the review a history of the first works on the field of orexin and its receptors are described. Hypothalamic orexin-producing cells and effects on brain functions are described. The effects of orexins and their receptors on eating behavior, wakefulness and positive reinforcement are described. Then, the effects of orexins on narcolepsy was analyzed. The participation of orexins in the mechanisms of reinforcement and dependence and the key role of orexins in the development of addictive behaviors is described. The special role of orexin in the formation of ethanol dependence is shown. Next, the issue of the action of orexins under stress was considered. Orexins have been shown to play an important role in the regulation of the nervous and humoral mechanisms mediating the formation of emotional memory associated with negative experience. It is concluded that orexin can modulate the estimation of stress and probability for reaching stimulus. In this regard, orexin antagonists can be considered as possible promising means of preventing and treating disorders of the anxiety-phobic spectrum, as well as disorders associated with the use of addictive drugs caused by stress and environmental stimuli.

Keywords: orexins; orexin receptors; reinforcement; stress; extended amygdala; narcolepsy. 


\section{1. РОЛЬ ОРЕКСИНА В ОРГАНИЗАЦИИ АДАПТИВНОГО ПОВЕДЕНИЯ}

\section{1. Орексин и орексиновые рецепторы}

Орексины А и В (или гипокретин-1 и гипокретин-2 соответственно) были дважды независимо описаны как лиганды орфанного GPCRHFGAN72 рецептора (OX1R) из экстракта гипоталамуса крысы [110] и как транскрипты изолированных цепочек матричной рибонуклеиновой кислоты (МРНК) из гипоталамуса крысы [54]. Два независимых эпизода открытия породили двойственную номенклатуру. Изначально название «орексин» (от греч. «орє乡ı » - аппетит) было дано для указания на способность новооткрытого пептида воздействовать на пищевое поведение. Наименование «гипокретин» указывает на некоторое структурное сходство пептидов с гормоном энтеральной эндокринной системы - секретином. В сущности, ни одно из этих названий не отражает функционального потенциала описываемых пептидов. В данной работе мы принимаем название «орексин» в качестве основного, во избежание разночтений.

Орексиновый рецептор 1-го типа (OX1R) был изначально идентифицирован в качестве орфанного рецептора, экспрессируемого в головном мозге человека [111]. Впоследствии, посредством tBLASTnc секвенирования был обнаружен орексиновый рецептор 2-го типа (OX2R).

Орексины А и В - нейропептиды, образующиеся исключительно в ограниченной популяции нейронов латерального гипоталамуса и реализующие нейромодулирующее и нейромедиаторное действия через два сопряженных с G-белком рецептора - рецепторы орексина 1-го и 2-го типов (OX1R и OX2R) [37-40, 82, 83, 86].

Орексины - новое семейство консервативных нейропептидов без значимых структурных сходств с известными регуляторными нейропептидами. Орексин А - пептид, состоящий из 33 аминокислот, массой 3562 Да, имеющий два внутрицепочечных дисульфидных мостика. Его $\mathrm{N}$-терминальный конец имеет полиглутамильный остаток, С-терминальный конец - амидный. Первичная структура орексина А полностью идентична у ряда млекопитающих (человека, крысы, мыши, коровы, овцы, собаки и свиньи). Крысиный орексин В, состоящий из 28 аминокислот, - амидированный с С-конца линейный пептид массой 2937 Да, на 46 \% сходный с последовательностью орексина А. С-терминальная половина орексина В демонстрирует высокое сходство с орексином A (73 \%), в то время как N-терминальная половина варьируется. Ряд исследований показывает высокое сродство структуры орексинов А и В млекопитающих с орексинами других позвоночных, в частности птиц, земноводных и лучеперых рыб [65].

Орексины А и В продуцируются из общего полипептидного предшественника, препроорексина, путем посттранскрипционного протеолиза, вероятно, конвертазами прогормона.
Реализация действия орексинов в клетке происходит посредством активации специфических пресинаптических орексиновых рецепторов OX1R и OX2R [130]. Идентичность аминокислотного состава первичной структуры OX1R и OX2R составляет $64 \%$. Идентичность аминокислотных последовательностей при сравнении человека и крысы для каждого из этих рецепторов составляет 94 и $95 \%$ соответственно [110]. OX1R имеет гораздо большую афинность к орексину A, чем к орексину B, в то время как OX2R имеет примерно равную афинность для обоих типов орексинов [111] и представлен двумя формами OX2R и и OX2Rß [129]. OX1R соединен c G-протеином класса $\mathrm{Gq} / 11$, и его активация приводит к активации фосфолипазы C с последующим запуском фосфодитилинозитольного каскада. OX2R соединен как c Gq/11, так и с Gi/o ингибиторными протеинами при экспрессии в клеточных линиях [139]. Было показано влияние антагониста орексина OX1R SB-408124 на кариотипическую стабильность и экспрессию рибосомных цистронов периферической крови у крыс [5-7].

В центральной нервной системе исследования гибридизации in situ продемонстрировали, что мРНК орексиновых рецепторов экспрессируется в структурах головного мозга, где содержится мРНК орексинов. Распределение OX1R и OX2R совпадает только частично, и имеющиеся различия демонстрируют, что, по-видимому, их функции в организации работы ЦНС различаются. Экспрессия OX1R обнаруживается в таких структурах головного мозга, как обонятельные луковицы, префронтальная и инфралимбическая кора, гиппокамп, центральное ядро миндалины, паравентрикулярное таламическое ядро, передний гипоталамус, дорсальное ядро шва, вентральная область покрышки, дорсолатеральная область покрышки [95], а также в тканях периферических органов: щитовидной железы, тонкого кишечника, почек, надпочечников и яичников [102]. OX2R обнаруживают в миндалине и ядре ложа конечной полоски, паравентрикулярном ядре таламуса, дорсальном шве, сосцевидных телах, вентральной области покрышки, дорсолатеральной области покрышки $[129,140]$ и в тканях аденогипофиза, надпочечников и легких [129]. OX1R способен формировать гетеродимерные структуры с каппа-опиоидными рецепторами (KOR) [49] и каннабиноидными рецепторами CB1 [58], для OX2R характерна гетеродимеризация между двумя вариациями рецептора [59, 129].

\section{2. Орексиновые нейроны гипоталамуса}

Орексинпродуцирующие нейроны (орексиновые нейроны) - немногочисленная группа клеток, расположенных исключительно в латеральном гипоталамусе крыс [99, 100]. Аксоны этих клеток образуют обширную проекционную сеть, охватывающую различные структуры головного мозга [99, 107, 109]. Наиболее интенсивно иммуногистохимическое окрашивание орексиновых нервных окончаний в головном 
мозге наблюдается в паравентрикулярном ядре таламуса, аркуатном ядре гипоталамуса, туберомамиллярном и латеральном мамиллярном ядрах, ядре шва и голубоватом месте [99, 135]. Орексин колокализуется с динорфином [50], глутаматом [36, 91]. Орексиновые нейроны иннервируются из латерального парабрахеального ядра, вентролатерального преоптического ядра, медиальной и латеральной преоптической областей, основания переднего мозга, заднего и дорсомедиального гипоталамуса, вентральной области покрышки и медиального ядра шва [57]. Данные структуры мозга регулируют активность орексиновых нейронов по нейромедиаторному механизму. Введение неизбирательного холиномиметика карбахола активирует 27 \% и ингибирует 6 \% орексиновых нейронов через М3-мускариновые рецепторы [90, 110]. Норадреналин и серотонин (5НТ) вызывают гиперполяризацию мембран орексиновых нейронов через активацию G-белков, регулирующих состояние $\mathrm{K}^{+}$-каналов через альфа-2-адренорецепторы и 5HT1A- рецепторы [105]. Несмотря на то что орексиновые нейроны и не экспрессируют дофаминовые рецепторы, дофамин может вызывать гиперполяризацию мембран орексиновых нейронов, опосредованно альфа-2адренорецепторами [133]. Таким образом, серотониновые и катехоламиновые нейроны, по-видимому, осуществляют тормозную обратную связь с орексиновыми нейронами. Указанный механизм обратной связи может стабилизировать активность как орексиновых, так и моноаминергических нейронов.

Было также показано, что агонисты NMDA рецепторов возбуждают орексиновые нейроны, тогда как антагонисты NMDA рецепторов снижают их активность [132, 136].

Использование внутриклеточного кальциевого индикатора (Yс2.1) в орексинпродуцирующих нейронах на модели трансгенных мышей позволило обнаружить активность ряда соединений, влияющих на основные функции данных клеток. Обнаружено, что холецистокинин, нейротензин, окситоцин и вазопрессин оказывают возбуждаюшее действие [47, 48, 79, 80, 122, 124, 125], тогда как гамма-аминомасляная кислота (ГАМК), глюкоза, серотонин, норадреналин, пролактин и лептин оказывают тормозное действие на орексиновые нейроны [89]. Орексиновые нейроны также значительно подвержены колебаниям в уровне $\mathrm{CO}_{2}[81,131]$. Так как орексин влияет на респираторные функции, он может играть важную роль и в регуляции дыхания [98].

\section{3. Функциональная роль орексинов}

Орексин А и орексин В (или гипокретин-1 и гипокретин-2 соответственно) были первоначально описаны как модуляторы пищевого поведения в связи с локализацией орексинпродуцирующих клеток в ограниченной области латерального гипоталамуса, известного центра насыщения головного мозга $[69,73,74,126]$. Первые же детальные исследования позволили соотнести орексины с функцией регуляции цикла сон-бодрствование, в частности с механизмами пробуждения и поддержания бодрствующего состояния [54]. В дальнейшем была обнаружена связь орексинов, наряду с другими нейропептидами головного мозга, и системы положительного подкрепления [42-45]. Отмечается, что механизмы регуляции цикла сон-бодрствование в большей степени связаны с функционированием OX2R, в то время как регуляция системы положительного подкрепления - с активацией OX1R [17]. Этот факт допускает возможность разработки средств фармакологической коррекции, избирательно изменяющих активность OX1R или OX2R рецепторов, для лечения аддикции и расстройств сна соответственно $[66,78]$. Недостаточность выработки орексина или рецепторов к нему приводит к развитию нарколепсии. Таким образом, предполагается, что орексиновая регуляция критически важна для поддержания состояния бодрствования. Орексин активирует моноаминергические, холинергические и гистаминергические нейроны, необходимые для поддержания состояния бодрствования, и получают обширную обратную связь от структур лимбической системы [67, 68, 121]. Орексиновые нейроны имеют реципрокные соединения с аркуатным ядром гипоталамуса, регулирующим потребление пищи. Также участие орексина в регуляции пищевого поведения и энергетического обмена подтверждается наличием у орексиновых нейронов чувствительности к лептину, грелину и колебаниям уровня глюкозы [102]. Орексиновые нейроны также имеют связи с дофаминергической подкрепляюшей системой мозга [25-27, 34]. Таким образом, орексиновая регуляция играет роль в формировании эмоционального подкрепления, энергетическом гомеостазе, пищевом поведении и поддержании состояния бодрствования [93].

Дефицит орексина приводит к развитию нарколепсии - расстройству сна, характеризующемуся непреодолимыми приступами дневной сонливости, эпизодами спонтанного засыпания, приступами катаплексии и дезорганизацией REM-фазы сна. Это одно из самых распространенных хронических расстройств сна, поражающее приблизительно 1 на 2000 человек, однако нередко не диагностируемое [113]. Люди, страдающие нарколепсией, ощущают постоянную избыточную дневную сонливость, крайней формой которой являются приступы внезапного засыпания в нетипичное время, в том числе во время эпизодов активности. Другим значимым симптомом является катаплексия, проявляющаяся ослаблением постурального мышечного тонуса от легких форм, сопровождающихся отвисанием челюсти и утратой членораздельной речи, до полной потери тонуса постуральной мускулатуры. Не менее типичны спонтанные приступы сонного паралича, сопровождающиеся сноподобными галлюцинациями и мозговой активностью, характерной для REM-фаз сна. Эти симптомы позволяют говорить о ключевой роли орексинов в поддержании и стабилизации состояния бодрствования, а также торможения фазы быстрого сна [112-114]. 
Животными моделями для изучения нарколепсии являются нокаутные по генам препроорексина и генам Ox1r и Ox2r мыши и собаки, мутантные по генам Ox1r и Ox2r [111]. Мыши, нокаутные по генам препроорексина и OX1R и OX2R, демонстрируют симптомы, сходные с таковыми у людей, страдающими нарколепсией. У них наблюдаются приступы катаплексии, дезорганизация REM-фазы сна, атипично высокая сонливость и значительно фрагментированные циклы сна-пробуждения [111].

Изучение патоморфологической картины головного мозга собак, а также постсмертное исследование тканей мозга людей, страдающих нарколепсией, демонстрирует резкое снижение числа орексинпродуцирующих нейронов на 80-100 \% в гипоталамусе, а также отсутствие иммунореактивного окрашивания орексинов в коре и стволовых структурах, обычно обнаруживающих орексинергические проекции [101]. Наличие в анамнезе нарколепсии в сочетании с катаплексией коррелирует так же с низким уровнем орексина А в цереброспинальной жидкости [94].

Причина деградации орексиновых нейронов при нарколепсии до сих пор точно не установлена. Ассоциация симптомов нарколепсии и носительства гена $H L A-D Q B 1{ }^{*} 0602$ указывает на вероятную аутоиммунную реакцию, приводящую к дегенерации орексинпродуцирующих клеток и возникающую либо спорадически, либо на фоне перенесенного инфекционного заболевания [113]. В то же время специфические антитела к орексиновым нейронам не обнаруживаются в сыворотке крови и цереброспинальной жидкости пациентов с нарколепсией. Таким образом, понимание роли дефицита орексина при нарколепсии говорит о его ключевой роли в регуляции цикла сон-бодрствование, особенно в реализации пробуждения и поддержания состояния бодрствования.

\section{2. УЧАСТИЕ ОРЕКСИНОВ В МЕХАНИЗМАХ ПОДКРЕПЛЕНИЯ И ЗАВИСИМОСТИ}

2.1. Ключевая роль орексинов в развитии аддиктивных форм поведения

Интерес к исследованию роли орексинов в реализации аддиктивных форм поведения изначально возник в ходе изучения нарколепсии. Показано, что пациенты, страдающие нарколепсией, вынужденные постоянно принимать психостимуляторы, оказываются устойчивыми к развитию лекарственной зависимости. Сходная картина наблюдается и в отношении наркотических анальгетиков [55, 92].

Согласно современным представлениям орексины занимают ключевую позицию в развитии аддиктивных форм поведения и поведения, связанного с системой положительного подкрепления [9, 10, 12, 13]. Особенно важна роль орексинов в реализации условных реакций потребления и злоупотребления веществами с аддиктивным потенциалом на фоне стрессорных факторов или сигналов внешней среды [11, 15, 16, 64].
Структурной основой данного действия орексинов является, по-видимому, обширная проекционная сеть связей орексинпродуцирующих нейронов и структур мезокортиколимбической системы [21, 60-62, 71] и системы расширенной миндалины [22-24]. Эти связи опосредуют поведение, связанное с аддикцией [54]. Исследования на животных показали неравномерное участие орексиновых нейронов в работе системы положительного подкрепления. Орексиновые нейроны, вовлеченные в процессы подкрепления, располагаются латерально, тогда как более медиально расположенные орексинпродуцирующие клетки вовлечены в пробуждение и реакции на стресс [72]. Функционирование орексиновых рецепторов также, вероятно, дихотомично. OX1R играет ведущую роль в реакциях подкрепляющего поведения [14, 103, $104,106]$, тогда как OX2R регулирует циклы сна-бодрствования [72]. Таким образом, при независимости этих функций можно говорить о поиске селективных антагонистов OX1R и OX2R (SORA) в качестве перспективных лекарственных средств для лечения аддиктивных расстройств и расстройств сна [66].

В настоящее время остается открытым вопрос о соотношении функций орексинов, в частности, понимание связи между пробуждением и подкреплением. Часто пробуждение служит подкрепляющим стимулом, а подкрепление индуцирует бодрствование [15]. Но каким образом это отражает взаимосвязи между латеральными и медиальными группами орексиновых нейронов или OX1R и OX2R? Следует ли рассматривать дихотомичность функций орексинов, как составляющие компоненты единой регуляторной системы, определяющей предрасположенность к стимулам и организацию мотивационного поведения? В этом смысле потенциальным направлением фармакологических исследований является разработка неселективных антагонистов OX1R/OX2R (DORA) для получения более широкого терапевтического спектра [134].

Функциональные основы орексиновой регуляции на сегодняшний момент активно исследуются. Показано, что орексиновые нейроны отвечают на подкрепляющие стимулы, включая пищу, половое влечение и аддиктивные вещества [56, 122]. Блокада OX1R угнетает восстановление условных поведенческих реакций в отношении тяги к аддиктивным средствам или пище [51, 74, 75]. В то же время эффекты орексиновой регуляции разнятся в зависимости от типа аддиктивного средства. Так, OX1R антагонисты снижают тягу к этанолу, амфетамину и героину, но не к кокаину. Эта совокупность общих и дифференциальных эффектов может отражать способность орексина к усилению ответа дофаминовых нейронов вентральной области покрышки на поступающие стимулы [70].

Роль орексиновой регуляции в реализации аддиктивного поведения успешно воспроизводится в экспериментальных животных моделях. В то же время картина влияний орексина на процессы под- 
крепления далека от полноты. Во многом это происходит вследствие комплексного вовлечения орексина в различные аспекты тяги к препаратам, такие как отвращение и мотивация потребления пищи, взаимодействие с процессами павловского обусловливания и инструментального обусловливания [24]. Отдельной проблемой является обширность диффузной сети орексиновых волокон и многочисленность структур головного мозга, активность которых модулируется этими волокнами.

\section{2. Роль орексина в формировании зависи- мости от этанола}

Экспериментально подтверждено участие орексинов в регуляции потребления этанола [1-4, 53, 77]. Внутриструктурное введение орексина в латеральный гипоталамус и паравентрикулярное ядро гипоталамуса стимулировало потребление алкоголя, независимо от приема пищи, а введение орексина в прилежащее ядро угнетало этот процесс у крыс линии Sprague Dawley [117]. Введение селективного антагониста OX1R SB-334867 снижало потребление этанола у крыс линии Sprague Dawley в условиях теста свободного выбора вода-этанол [85, 88, 95]. Это подтверждает высокую вовлеченность орексиновой регуляции в процесс потребления алкоголя и свидетельствует о возможной роли орексина в формировании алкогольной аддикции.

Хроническая алкоголизация вызывает изменения в экспрессии мРНК препроорексина и внутриструктурного уровня орексина. На фоне хронического потребления этанола отмечается увеличение экспрессии мРНК в латеральном гипоталамусе предпочитающих этанол крыс [84, 96, 97]. С другой стороны, показано, что хроническое потребление этанола у крыс в условиях полупринудительной алкоголизации сопровождается снижением внутриструктурного и периферического уровня орексина [123]. Эти исследования свидетельствуют, что роль орексина в системе подкрепления потребления этанола может быть различной и, возможно, зависит от сопутствующих факторов, таких как стресс [3].

Показана роль OX1R в реализации подкрепляющих свойств этанола в модели самовведения. Системное введение SB-334867 снижало частоту самовведения этанола у предпочитающих этанол крыс при использовании как фиксированного, так и прогрессивного режимов подкрепления [76, 119]. Однако в другой серии экспериментов селективный OX2R антагонист JNJ-10397049 снижал частоту самовведения этанола при использовании фиксированного режима подкрепления, в то время как SB-334867 не продемонстрировал достоверного эффекта. Таким образом, OX2R также потенциально могут играть важную роль в реализации подкрепляющего действия этанола, в то время как действие специфических OX1R антагонистов может быть результатом неспецифического действия на OX2R при высоких дозировках (20-30 мг/кг) [118].
Роль орексиновой регуляции в реализации подкрепления потребления этанола также исследована на модели условной реакции предпочтения места (УРПМ). Показано, что селективные антагонисты OX1R SB-334867 и SB-408124 снижают экспрессию УРПМ этанола [128]. Селективный OX2R антагонист JNJ-10397049 угнетал формирование УРПМ этанола, а так же снижал ее экспрессию и восстановление у мышей [118].

Вероятно, орексин вовлечен и в механизмы рецидивирования злоупотребления этанола на фоне его отмены, что демонстрируют исследования на моделях восстановления. Системное введение SB-334867 снижало восстановление предпочтения этанола, вызываемое световыми стимулами [76] и введением йохимбина или нейропептида S в латеральный гипоталамус [46], а интраназальное введение SB-408124 снижало возобновление предпочтения этанола, вызванного обстановочными стимулами [123]. Орексин может также вовлекаться в восстановление подкрепляющего действия этанола, связанного с активацией Fos в нейронах латерального гипоталамуса, дорсомедиального гипоталамуса, перифорникальной зоны, прелимбической и орбитофронтальной зонах префронтальной коры и в прилежащем ядре [52].

Показана значимая роль орексинов в поддержании тяги к этанолу в течение периода абстиненции. Уровень орексина в центральном ядре миндалины, гиппокампе, а также периферической крови хронически алкоголизированных крыс резко возрастает на вторые сутки после отмены этанола [18]. Показано, что действие орексина через OX1R инициирует стимул-зависимую тягу к этанолу как при наличии, так и при отсутствии подкрепления этанолом [138]. SB-334867 блокировал тягу к алкоголю, вызванную абстиненцией у предпочитающих этанол крыс, обученных самовведению, на фоне доступности инициирующей дозы. Также системное введение SB-334867 блокировало выработку Fos в структурах мозга, ассоциированных с предпочтением этанола, индуцированную обстановочными факторами [76]. Таким образом, орексиновая регуляция может являться одним из ключевых механизмов возобновления угашенного предпочтения этанола [137].

В исследованиях на людях установлена взаимосвязь между потреблением алкоголя и динамикой орексина периферической крови [20, 127]. Показано, что уровень МРНК орексина А был ниже у больных алкоголизмом в стадии ремиссии после успешно перенесенной детоксикации, чем у тех, кто подвергался острой отмене в клинике. Показано, что уровень орексина в плазме крови положительно коррелировал с выраженностью физического дискомфорта и психологического стресса, испытываемых пациентами с алкоголизмом в ходе острой отмены алкоголя в клинике [127].

Таким образом, роль орексина в формировании и поддержании тяги к этанолу является очевидным фактом. В случае с этанолом участие орексиновой 
регуляции в поддержании условно подкрепляющего действия, а также стимул- и стресс-индуцированного возобновления тяги видится анологичным процессам, наблюдаемым на других формах аддикций. Ведущую роль здесь, вероятно, играет активация OX1R [31]. Однако OX2R также могут вносить собственный вклад в механизмы предпочтения этанола [118].

\section{3. УЧАСТИЕ ОРЕКСИНОВ В РЕГУЛЯЦИИ CTPECCA}

Ряд недавних исследований выявил роль орексинов в регуляции эмоционального поведения и эмоциональной памяти. Обоснованием этой роли орексиновой регуляции служит тесное двунаправленное взаимодействие орексиновых нейронов с эмоциогенными структурами головного мозга, такими как ядро ложа конечной полоски, голубоватое место, центральное и дорзомедиальное ядра миндалины, гиппокамп, медиальная префронтальная кора.

Принимая во внимание важную роль кортиколиберина (CRF) в регуляции стрессорных реакций, также представляет интерес то, что орексиновые волокна расположены в непосредственной близости от нейронов, продуцирующих CRF в паравентрикулярном ядре и миндалине. Наличие эфферентной орексиновой иннервации этих структур позволяет предположить, что орексины могут модулировать работу гипоталамо-гипофизарно-надпочечниковой оси, влияя на гуморальную составляющую стрессовых реакций $[8,19,35,115]$. Орексин А увеличивает секрецию кортизола и кортикостерона адренокортикальными клетками человека и крысы [132]. Внутрижелудочковое введение орексина А повышает концентрацию кортикостерона и адренокортикотропного гормона (АКТГ) в плазме крови у крыс [58]. Эти данные позволяют предполагать аналогичное действие орексинов и на экстрагипоталамические источники CRF в головном мозге, представленные системой расширенной миндалины, куда вошли ядро ложа конечной полоски, центральное ядро миндалины, медиальная часть прилежащего ядра и безымянная субстанция. Система расширенной миндалины влияет на стресс-зависимое поведение, инициируя эмоционально-мотивированные ответы и опосредуя анксиогенные эффекты CRF [22, 32-34]. CRF регулирует защитные инстинктивные формы эмоционального поведения, такие как страх, тревога, фрустрация и их угашение, в то время как дофаминергическая система - гедонистические компоненты поведения: удовольствие, удовлетворение и стремление к ним $[21,26]$. С этих позиций орексин в мезокортиколимбической системе и дофаминергические терминали, идущие из вентральной области покрышки, могут рассматриваться как регуляторы, прежде всего, положительных эффектов - удовлетворения потребности в пище, воде, реализация аддиктивного поведения. С другой стороны, как часть экстрагипоталамической системы CRF, орексиновая регуляция затрагивает главным образом негативные эмоциональные реакции [28-30].

Исследования на людях показали, что страдающие нарколепсией, демонстрируют снижение функциональной активности миндалины и нарушение взаимодействия миндалины и префронтальной коры при воздействии неприятного раздражителя [129]. Проведенные методом микродиализа исследования показывают увеличение выделения орексина А в ядрах миндалины у человека при активном социальном взаимодействии, переживании положительных эмоций и гнева, что также поддерживает гипотезу об участии орексинов в регулировании эмоциональных реакций и реализации реакции на стресс [41].

Участие орексиновой регуляции в модуляции страха также было продемонстрировано на животных моделях. Мыши, нокаутные по гену Ox1r, показали нарушение реакции замирания и снижение экспрессии нейронального маркера активности zif268 в латеральной миндалине в ситуациях прямого и обусловленного страха. Неселективный OX1R/OX2R антагонист алморексант снижал проявление обусловленного страха у крыс [120], а также увеличивал экспрессию мРНК препроорексина [49]. Следует отметить, что восстановление экспрессии OX1R в норадренергических нейронах голубоватого места у нокаутных по гену Ox1r мышей, индуцированное внесением аденовирусного вектора, увеличивает активность латерального ядра миндалины и нормализует реакцию на пугающие раздражители [108]. Аналогичное включение OX1R в регуляцию взаимодействия голубоватого места и миндалины изучено фармакологическими и оптогенетическими методами. Фармакологическая блокада OX1R в голубоватом месте путем микроинъекции SB334867 препятствовала реализации условной реакции на пугающий звуковой сигнал. В то же время оптической стимуляции орексиновых волокон было достаточно, чтобы усилить эту реакцию [129].

В отличие от нокаутных по гену Ox1r, нокаутные по гену Ox2r мыши демонстрировали снижение частоты и времени замирания при воздействии пугающего условного раздражителя, но в то же время нормальное замирание в ответ на безусловный пугающий раздражитель [129]. Внутрижелудочковое вливание селективного OX2R антагониста TCSOX2-29 не оказывало влияния на замирание в ответ на условный раздражитель [132]. Эти данные указывают на различную роль OX1R и OX2R в формировании условной реакции избегания стрессирующего воздействия, что может быть связано с их преимущественным расположением в разных структурах мозга.

Орексины также модулируют угашение условных реакций избегания. Например, блокада OX1R с помощью SB334867 способствует ускорению угашения избегания, индуцированного воздействием обстановочных стимулов [63]. Применение SB408124 у крыс на фоне однократной острой психотравмирующей 
ситуации оказывает анксиолитическое действие в приподнятом крестообразном лабиринте [123]. Эти данные позволяют предположить потенциал этой фармакологической мишени в отношении заболеваний фобического спектра и посттравматического стрессового расстройства. Блокада OX2R с помощью TCS-OX2-29 не влияла на угашение реакции избегания [63]. Показана связь орексиновой регуляции и неспецифического избегающего поведения у крыс [108]. Аналогичная неадекватная реакция на травмирующий опыт у человека считается признаком посттравматического стрессового расстройства и сходных тревожных расстройств. Длительная блокада OX1R/OX2R алморексантом снижает риск развития и закрепления неспецифического избегания у крыс, позволяя предполагать вклад орексинов в этот процесс [63].

Исследования показывают, что таламическое паравентрикулярное ядро регулирует модуляцию реакции страха в латеральном отделе центрального ядра миндалины [116], что имеет важное значение в отношении поддержания долговременной памяти о травмирующем опыте [120]. Паравентрикулярное ядро таламуса имеет большое количество эфферентных проекций орексиновых нейронов [116] и может участвовать в реализации отрицательной эмоциональной составляющей поведения, опосредованного орексиновой регуляцией. Микроинъекции орексинов А и В в данную область мозга оказывали анксиогенное действие на животных в приподнятом крестообразном лабиринте [87]. В то же время оптогенетическая стимуляция орексиновых нейронов индуцировала экспрессию OX1R в клетках паравентрикулярного ядра таламуса и повышала тревожность крыс в тесте социального взаимодействия [73]. Следовательно, можно предположить, что орексины также способны модулировать тревожность, действуя на паравентрикулярное ядро таламуса, принимая во внимание его роль в обработке памяти, ассоциированной со стрессом.

Таким образом, орексины играют значимую роль в регуляции нервных и гуморальных механизмов, опосредующих формирование эмоциональной памяти, ассоциированной с негативным опытом. Активация OX1R в эмоциогенных структурах мозга способствует поддержанию аверсивных реакций и их углублению, вплоть до неспецифической реакции избегания. Действие OX1R антагонистов ускоряет исчезновение аверсивных воспоминаний.

В дополнение к описанным выше действиям на нейронную активность и поведение орексин также способствует запуску разнообразных вегетативных процессов, связанных со стрессом и/или высоким уровнем возбуждения. К ним относятся повышение среднего артериального давления, частоты сердечных сокращений, потребления кислорода и температуры тела.

Таким образом, орексин может модулировать оценку стресса и вероятности достижения подкрепляющего стимула. В связи с этим антагонисты орексина могут рассматриваться как возможные перспективные средства профилактики и лечения расстройств тревожно-фобического спектра, а также вызванных стрессом и окружающими стимулами среды, расстройств, связанных с приемом аддиктивных средств.

\section{ЛИТЕРАТУРА}

1. Айрапетов М.И., Сексте Э.А., Ереско С.О. Уровень мРНК рецепторов орексина первого типа (OX1R) в эмоциогенных структурах мозга крыс при их хронической алкоголизации // Вопросы наркологии. 2018. - № 8. - C. 18-25. [Ayrapetov MI, Sekste EA, Eresko SO. Orexin receptor type 1 (Ox1r) mRNA level in emotiogenic structures of the brain under chronic alcoholization. Voprosy narkologii. 2018;(8):18-25. (In Russ.)]

2. Виноградов П.М., Тиссен И.Ю., Хохлов П.П., и др. Система орексина и гормоны гипоталамо-гипофиз-надпочечниковой оси при экспериментальной алкоголизации у крыс. В кн.: Достижения современной фармакологической науки. Сборник материалов Всероссийской конференции молодых ученых, посвященной 150-летию Н.П. Кравкова / Под ред. Е.Н. Якушевой. - Рязань: РязГМУ, 2015. - С. 59-63. [Vinogradov PM, Tissen IYu, Khokhlov PP, et al. Sistema oreksina i gormony gipotalamo-gipofiz-nadpochechnikovoy osi pri eksperimental'noy alkogolizatsii u krys. In: Dostizheniya sovremennoy farmakologicheskoy nauki. Sbornik materialov Vserossiyskoy konferentsii molodykh uchenykh, posvyashchennoy 150-letiyu N.P. Kravkova. Ed. by E.N. Yakusheva. Ryazan': RyazGMU; 2015. P. 59-63. (In Russ.)]

3. Виноградов П.М., Тиссен И.Ю., Хохлов П.П., и др. Содержание АКТГ и КРФ в сыворотке крови крыс после введения антагонистов орексина А при экспериментальной алкоголизации // Обзоры по клинической фармакологии и лекарственной терапии. - 2015. T. 13. - № 2. - C. 14-19. [Vinogradov PM, Tissen IYu, Khokhlov PP, et al. Contents of ACTH and CRF in the rat blood serum after administration of orexin $A$ antagonists in experimental alcoholization. Reviews on Clinical Pharmacology and Drug Therapy. 2015;13(2):14-19. (In Russ.)]. https://doi.org/10.17816/RCF13214-19.

4. Виноградов П.М., Тиссен И.Ю., Хохлов П.П., и др. Гормоны оси гипоталамус-гипофиз-надпочечники при экспериментальной алкоголизации и воздействии антагонистов орексина А // Обзоры по клинической фармакологии и лекарственной терапии. - 2015. T. 13. - № S1. - C. 24-26. [Vinogradov PM, Tissen IYu, Khokhlov PP, et al. Gormony osi gipotalamus-gipofiz-nadpochechniki pri eksperimental'noy alkogolizatsii i vozdeystvii antagonistov oreksina A. Reviews on Clinical Pharmacology and Drug Therapy. 2015;13(S1):24-26. (In Russ.)]

5. Косякова Г.П., Лебедев А.А., Шабанов П.Д. Влияние антагониста орексина OX1R SB-408124 на кариотипическую стабильность и экспрессию рибосомных цистронов периферической крови крыс // Обзоры по клинической фармакологии и лекарственной терапии. - 2015. - Т. 13. - № S1. - С. 75-78. [Kosyakova GP, 
Lebedev AA, Shabanov PD. Vliyanie antagonista oreksina OX1R SB-408124 na kariotipicheskuyu stabil'nost' i ekspressiyu ribosomnykh tsistronov perifericheskoy krovi krys. Reviews on Clinical Pharmacology and Drug Therapy. 2015;13(S1):75-78. (In Russ.)]

6. Косякова Г.П., Лебедев А.А., Шабанов П.Д. Влияние антагониста орексиновых OX1R-рецепторов SB-408124 на миелограмму костного мозга и лиеноцитограмму грызунов // Обзоры по клинической фармакологии и лекарственной терапии. - 2015. - Т. 13. - № S1. C. 78-80. [Kosyakova GP, Lebedev AA, Shabanov PD. Vliyanie antagonista oreksinovykh OX1R-retseptorov SB-408124 na mielogrammu kostnogo mozga i lienotsitogrammu gryzunov. Reviews on Clinical Pharmacology and Drug Therapy. 2015;13(S1):78-80. (In Russ.)]

7. Косякова Г.П., Лебедев А.А., Шабанов П.Д. Действие антагониста орексина OX1R SB-408124 на стабильность генома и функциональные изменения в половых клетках у самцов крыс // Обзоры по клинической фармакологии и лекарственной терапии. - 2015. - Т. 13. № S1. - C. 80-83. [Kosyakova GP, Lebedev AA, Shabanov PD. Deystvie antagonista oreksina OX1R SB-408124 na stabil'nost' genoma i funktsional'nye izmeneniya v polovykh kletkakh u samtsov krys. Reviews on Clinical Pharmacology and Drug Therapy. 2015;13(S1):80-83. (In Russ.)]

8. Лавров Н.В., Лебедев А.А., Смирнов А.А., и др. Нейропептиды и протективная функция мозга // Обзоры по клинической фармакологии и лекарственной терапии. - 2015. - Т. 13. - № S1. - С. 89-90. [Lavrov NV, Lebedev AA, Smirnov AA, et al. Neyropeptidy i protektivnaya funktsiya mozga. Reviews on Clinical Pharmacology and Drug Therapy. 2015;13(S1):89-90. (In Russ.)]

9. Лебедев А.А., Виноградов П.М., Шумилов Е.Г., и др. Исследование внутриструктурного действия нейропептидов (грелина, орексина, кортиколиберина) в прилежащем ядре для подкрепляющих свойств психоактивных веществ // Обзоры по клинической фармакологии и лекарственной терапии. - 2015. T. 13. - № S1. - C. 92-94. [Lebedev AA, Vinogradov PM, Shumilov EG, et al. Issledovanie vnutristrukturnogo deystviya neyropeptidov (grelina, oreksina, kortikoliberina) $v$ prilezhashchem yadre dlya podkreplyayushchikh svoystv psikhoaktivnykh veshchestv. Reviews on Clinical Pharmacology and Drug Therapy. 2015;13(S1):92-94. (In Russ.)]

10. Лебедев А.А., Шумилов Е.Г., Бычков Е.Р., и др. Роль орексина А в механизмах подкрепления в ядре ложа конечной полоски // Обзоры по клинической фармакологии и лекарственной терапии. - 2015. - Т. 13. - № 2. C. 20-26. [Lebedev AA, Shumilov EG, Bychkov ER, et al. Orexin A role in mechanisms of reinforcement in the bed nucleus of stria terminalis. Reviews on Clinical Pharmacology and Drug Therapy. 2015;13(2):20-26. (In Russ.)]. https:// doi.org/10.17816/RCF13220-26.

11. Лебедев А.А., Шумилов Е.Г., Букинич А.А., и др. Нейропептиды (грелин, орексин, кортиколиберин) при введении в центральное ядро миндалины действуют на подкрепляющие свойства аддиктивных средств // Обзоры по клинической фармакологии и лекарственной терапии. - 2015. - T. 13. - № S1. - C. 95-97. [Lebe- $\operatorname{dev}$ AA, Shumilov EG, Bukinich AA, et al. Neyropeptidy (grelin, oreksin, kortikoliberin) pri vvedenii v tsentral'noe yadro mindaliny deystvuyut na podkreplyayushchie svoystva addiktivnykh sredstv. Reviews on Clinical Pharmacology and Drug Therapy. 2015;13(S1):95-97. (In Russ.)]

12. Лебедев А.А., Шумилов Е.Г., Смирнов А.А., и др. Участие нейропептида орексина А в механизмах подкрепления, активируемых психостимуляторами // Наркология. - 2015. - Т. 14. - № 2 - С. 12-18. [Lebedev AA, Shumilov EG, Smirnov AA, et al. Uchastie neyropeptida oreksina A $v$ mekhanizmakh podkrepleniya, aktiviruemykh psikhostimulyatorami. Narkologiia. 2015;14(2):12-18. (In Russ.)]

13. Лебедев А.А., Шумилов Е.Г., Смирнов А.А., и др. Участие орексина А в механизмах подкрепления в ядре ложа конечной полоски / Тезисы докладов Всероссийской конференции «Нейрохимические механизмы формирования адаптивных и патологических состояний мозга»; Санкт-Петербург, 24-26 июня 2014. - СПб: Институт физиологии им. И.П. Павлова РАН, 2014. - С. 88. [Lebedev AA, Shumilov EG, Smirnov AA, et al. Uchastie oreksina $A v$ mekhanizmakh podkrepleniya $v$ yadre lozha konechnoy poloski. In: Proceedings of the All-Russian Conference «Neyrokhimicheskie mekhanizmy formirovaniya adaptivnykh i patologicheskikh sostoyaniy mozga»; Saint Petersburg, 24-26 Jun 2014. Saint Petersburg: Institut fiziologii im. I.P. Pavlova RAN; 2014. P. 88 (In Russ.)]

14. Смирнов А.А., Лебедев А.А., Шумилов Е.Г., и др. Исследование центральных эффектов нейропептидов системы расширенной миндалины (грелина, орексина, кортиколиберина) для подкрепляющих свойств психоактивных веществ // Обзоры по клинической фармакологии и лекарственной терапии. - 2015. T. 13. - № S3. - C. 153-155. [Smirnov AA, Lebedev AA, Shumilov EG, et al. Issledovanie tsentral'nykh effektov neyropeptidov sistemy rasshirennoy mindaliny (grelina, oreksina, kortikoliberina) dlya podkreplyayushchikh svoystv psikhoaktivnykh veshchestv. Reviews on Clinical Pharmacology and Drug Therapy. 2015;13(S3):153-155. (In Russ.)]

15. Тиссен И.Ю., Виноградов П.М., Хохлов П.П., и др. Орексиновая система мозга участвует в механизмах условного подкрепления / Сборник материалов Всероссийской конференции молодых ученых, посвященной 150-летию Н.П. Кравкова «Достижения современной фармакологической науки»; Рязань, 22-24 октября 2015. - Рязань: РИО РязГМУ, 2015. C. 285-288. [Tissen IYu, Vinogradov PM, Khokhlov PP, et al. Oreksinovaya sistema mozga uchastvuet $v$ mekhanizmakh uslovnogo podkrepleniya. In: Proceedings of the The All-Russian Conference of Young Scientists with International Participation Dedicated to the $150^{\text {th }}$ Birthday of Academician N.P. Kravkov "Dostizheniya sovremennoy farmakologicheskoy nauki”; Ryazan', 22-24 Oct 2015. Ryazan': RIO RyazGMU; 2015. P. 285-288. (In Russ.)]

16. Тиссен И.Ю., Виноградов П.М., Хохлов П.П. Особенности действия орексина головного мозга в организации эмоционального и исследовательского поведения у крыс / Сборник материалов Всероссийской конференции молодых ученых, посвященной 150-летию Н.П. Кравкова «Достижения современной фармакологической науки»; 
Рязань, 22-24 октября 2015. - Рязань: РИО РязГМУ, 2015. - C. 289-293. [Tissen IYu, Vinogradov PM, Khokhlov PP. Osobennosti deystviya oreksina golovnogo mozga $v$ organizatsii emotsional'nogo i issledovatel'skogo povedeniya $u$ krys. In: Proceedings of the The All-Russian Conference of Young Scientists with International Participation Dedicated to the $150^{\text {th }}$ Birthday of Academician N.P. Kravkov "Dostizheniya sovremennoy farmakologicheskoy nauki”; Ryazan', 22-24 Oct 2015. Ryazan': RIO RyazGMU; 2015. p. 289-293. (In Russ.)]

17. Тиссен И.Ю., Виноградов П.М., Хохлов П.П., и др. Роль орексиновой системы в механизмах условного предпочтения // Обзоры по клинической фармакологии и лекарственной терапии. - 2015. - Т. 13. - № S1. C. 166-167. [Tissen IYu, Vinogradov PM, Khokhlov PP, et al. Rol' oreksinovoy sistemy v mekhanizmakh uslovnogo predpochteniya. Reviews on Clinical Pharmacology and Drug Therapy. 2015;13(S1):166-167. (In Russ.)]

18. Тиссен И.Ю., Виноградов П.М., Хохлов П.П., и др. Участие орексина в организации эмоционального и исследовательского поведения // Обзоры по клинической фармакологии и лекарственной терапии. - 2015. - Т. 13. - № S1. - С. 168-169. [Tissen IYu, Vinogradov PM, Khokhlov PP, et al. Uchastie oreksina v organizatsii emotsional'nogo i issledovatel'skogo povedeniya. Reviews on Clinical Pharmacology and Drug Therapy. 2015;13(S1):168-169. (In Russ.)]

19. Тиссен И.Ю., Якушина Н.Д., Лебедев А.А., и др. Эффекты антагониста OX1R рецепторов орексина A SB-408124 на компульсивное поведение и уровень тревожности после витального стресса у крыс // Обзоры по клинической фармакологии и лекарственной терапии. 2018. - T. 16. - № 1. - С. 34-42. [Tissen IYu, Yakushina ND, Lebedev AA, et al. Effect of SB-408124, an orexin A OX1R receptor antagonist, on the compulsive behavior and the level of anxiety after the vital stress in rats. Reviews on Clinical Pharmacology and Drug Therapy. 2018;16(1):34-42. (In Russ.)]. https://doi.org/10.17816/RCF16134-42.

20. Хохлов П.П., Бычков Е.Р., Сексте Э.А., и др. Динамика содержания нейроактивных пептидов в периферической крови у крыс при экспериментальной хронической алкоголизации (на модели грелин-орексин-кортиколиберин) // Обзоры по клинической фармакологии и лекарственной терапии. - 2013. - Т. 11. - № S. - С. 146-148. [Khokhlov PP, Bychkov ER, Sekste EA, et al. Dinamika soderzhaniya neyroaktivnykh peptidov v perifericheskoy krovi u krys pri eksperimental'noy khronicheskoy alkogolizatsii (na modeli grelin-oreksin-kortikoliberin). Reviews on Clinical Pharmacology and Drug Therapy. 2013;11(S):146-148. (In Russ.)]

21. Шабанов П.Д., Лебедев А.А. Подкрепляющие системы мозга: локализация, нейрохимическая организация, участие в формировании зависимости от психостимуляторов // Психофармакология и биологическая наркология. - 2001. - Т. 1. - № 1. - C. 2-5. [Shabanov PD, Lebedev AA. Podkreplyayushchie sistemy mozga: lokalizatsiya, neyrokhimicheskaya organizatsiya, uchastie $v$ formirovanii zavisimosti ot psikhostimulyatorov. Psychopharmacology and biological narcology. 2001;1(1):2-5. (In Russ.)]

22. Шабанов П.Д., Лебедев А.А. Структурно-функциональная организация системы расширенной миндалины и ее роль в подкреплении // Обзоры по клинической фармакологии и лекарственной терапии. - 2007. - Т. 5. № 1. - C. 2-16. [Shabanov PD, Lebedev AA. Strukturnofunktsional'naya organizatsiya sistemy rasshirennoy mindaliny i ee rol' v podkreplenii. Reviews on Clinical Pharmacology and Drug Therapy. 2007;5(1):2-16. (In Russ.)]

23. Шабанов П.Д., Лебедев А.А. Угнетение самостимуляции латерального гипоталамуса опиатами и опиоидами, вводимыми в центральное ядро миндалины // Российский физиологический журнал им. И.М. Сеченова. - 2011. - Т. 93. - № 2. - С. 27-35. [Shabanov PD, Lebedev AA. The extended amygdala system and selfstimulation of the lateral hypothalamus in rats: modulation with opiates and opioids. Ross Fiziol Zh Im I M Sechenova. 2011;93(2):27-35. (In Russ.)]

24. Шабанов П.Д., Лебедев А.А. Нейрохимические механизмы прилежащего ядра, реализующие подкрепляющие эффекты самостимуляции латерального гипоталамуса // Медицинский академический журнал. - 2012. - Т. 12. № 2. - C. 68-76. [Shabanov PD, Lebedev AA. Neurochemical mechanisms of the nucleus accumbens realizing the reinforcing effects of self-stimulation of the lateral hypothalamus. Med Akad Z. 2012;12(2):68-76. (In Russ.)]

25. Шабанов П.Д., Лебедев А.А., Морозов В.И., и др. Эффекты внутрижелудочкового введения орексина и его антагониста на подкрепляющие свойства психоактивных веществ // Обзоры по клинической фармакологии и лекарственной терапии. - 2015. - Т. 13. - № 4. C. 29-36. [Shabanov PD, Lebedev AA, Morozov VI, et al. Effects of intraventricular administration of orexin and its antagonist on the reinforcing properties of psychoactive drugs. Reviews on Clinical Pharmacology and Drug Therapy. 2015;13(4):29-36. (In Russ.)]

26. Шабанов П.Д., Лебедев А.А., Морозов В.И., и др. Активирующие эффекты фенциклидина на самостимуляцию мозга блокируются антагонистами OX1R рецепторов орексина при введении в структуры расширенной миндалины // Наркология. - 2017. - Т. 16. - № 2. C. 14-23. [Shabanov PD, Lebedev AA, Morozov VI, et al. Activating effects of phencyclidine on self-stimulation of the brain is blocked by OXR1 orexin receptor antagonists administered into the extended amygdala structures. Narkologiia. 2017;16(2):14-23. (In Russ.)]

27. Шабанов П.Д., Лебедев А.А., Морозов В.И., и др. Нейропептиды грелин и орексин участвуют в подкрепляющих эффектах психоактивных веществ разного механизма действия // Экспериментальная и клиническая фармакология. - 2015. - T. 78. - № S. - C. 63-64. [Shabanov PD, Lebedev AA, Morozov VI, et al. Neyropeptidy grelin i oreksin uchastvuyut $v$ podkreplyayushchikh effektakh psikhoaktivnykh veshchestv raznogo mekhanizma deystviya. Eksp Klin Farmakol. 2015;78(S):63-64. (In Russ.)]

28. Шабанов П.Д., Лебедев А.А., Морозов В.И. Участие рецепторов орексина структур расширенной миндалины в подкрепляющих эффектах спонтанной и активированной самостимуляции латерального гипоталамуса // Психическое здоровье. - 2016. - Т. 14. - № 8. - С. 13-21. [Shabanov PD, Lebedev AA, Morozov VI. Participation of orexin receptors of the extended amygdala system in the 
reinforcing effects of spontaneous and activated selfstimulation of the lateral hypothalamus. Psikhicheskoe zdorov'e. 2016;14(8):13-21. (In Russ.)]

29. Шабанов П.Д., Лебедев А.А., Морозов В.И., и др. Взаимодействие систем орексина и опиоидов в структурах парамигдалярного комплекса при оценке подкрепляющих эффектов спонтанной и активированной самостимуляции латерального гипоталамуса // Известия Российской Военно-медицинской академии. - 2017. T. 36. - № 1. - C. 37-45. [Shabanov PD, Lebedev AA, Morozov VI, et al. Interaction between orexin and opioids systems of the structures of paraamygdalar complex in the reinforcing effects of spontaneous and activated self-stimulation of the lateral hypothalamus. Izvestiya Rossiyskoy Voenno-meditsinskoy akademii. 2017;36(1):37-45. (In Russ.)]

30. Шабанов П.Д., Лебедев А.А., Морозов В.И., и др. Подкрепляющие свойства психоактивных веществ модулируются системой пептидов орексина головного мозга // Наркология. - 2016. - Т. 15. - № 4. C. 27-33. [Shabanov PD, Lebedev AA, Morozov VI, et al. The reinforcing properties of psychoactive drugs are modulated by the brain orexin peptides system. Narkologiia. 2016;15(4):27-33. (In Russ.)]

31. Шабанов П.Д., Лебедев А.А., Морозов В.И., и др. Возможное взаимодействие рецепторов орексина и опиоидов в структурах расширенной миндалины при оценке подкрепляющих эффектов спонтанной и активированной самостимуляции латерального гипоталамуса // Вопросы наркологии. - 2017. - № 2-3. C. 155-168. [Shabanov PD, Lebedev AA, Morozov VI, et al. A possible interaction of orexin and opioid receptors of the extended amygdala structures in the reinforcing effects of spontaneous and activated self-stimulation of the lateral hypothalamus. Voprosy narkologii. 2017;(2-3):155-168. (In Russ.)]

32. Шабанов П.Д., Лебедев А.А., Сексте Э.А., и др. Экспрессия гена орексинового рецептора OXR1 в мозге крыс при хронической алкоголизации и отмене этанола / МатериалыXXIII съезда физиологического общества им. И.П. Павлова; Воронеж, 18-22 сентября 2017 г. - Воронеж, 2017. - C. 2530-2532. [Shabanov PD, Lebedev AA, Sekste EA, et al. Ekspressiya gena oreksinovogo retseptora OXR1 v mozge krys pri khronicheskoy alkogolizatsii i otmene etanola. In: Proceedings of the $23^{\text {rd }}$ Congress of the Physiological Society. I.P. Pavlova; Voronezh, 18-22 Sep 2017. Voronezh; 2017. p. 2530-2532. (In Russ.)]

33. Шумилов Е.Г., Лебедев А.А., Букинич А.А., и др. Орексины системы расширенной миндалины при введении в ядро ложа конечной полоски действуют на подкрепляющие свойства аддиктивных средств ядра // Обзоры по клинической фармакологии и лекарственной терапии. - 2015. - Т. 13. - № S1. - C. 203-204. [Shumilov EG, Lebedev AA, Bukinich AA, et al. Oreksiny sistemy rasshirennoy mindaliny pri vvedenii $v$ yadro lozha konechnoy poloski deystvuyut na podkreplyayushchie svoystva addiktivnykh sredstv yadra. Reviews on Clinical Pharmacology and Drug Therapy. 2015;13(S1):203-204. (In Russ.)]

34. Шумилов Е.Г., Лебедев А.А., Бычков Е.Р., и др. Действие антагониста рецепторов орексина A OX(1) SB-408124 на самостимуляцию латерального гипоталамуса у крыс / Всероссийская конференция «Экспериментальная и клиническая фармакология: научные чтения», посвященная 90-летию со дня рождения профессора А.А. Никулина; Рязань, 25 октября 2013 г. - Рязань, 2013. [Shumilov EG, Lebedev AA, Bychkov ER, et al. Deystvie antagonista retseptorov oreksina A OX(1) SB-408124 na samostimulyatsiyu lateral'nogo gipotalamusa u krys. In: Proceedings of the All-Russian Conference "Eksperimental'naya i klinicheskaya farmakologiya: nauchnye chteniya" dedicated to the $90^{\text {th }}$ birthday of Professor A.A. Nikulin; Ryazan', 25 Oct 2013. Ryazan'; 2013. (In Russ.)]

35. Шумилов Е.Г., Лебедев А.А., Бычков Е.Р., и др. Действие антагониста рецепторов орексина A SB-408124 в ядре ложа конечной полоски на вызванную фенамином активацию самостимуляции у крыс // Обозрение психиатрии и медицинской психологии им. В.М. Бехтерева. - 2014. - № S. - C. 202-203. [Shumilov EG, Lebedev AA, Bychkov ER, et al. Deystvie antagonista retseptorov oreksina A SB-408124 v yadre lozha konechnoy poloski na vyzvannuyu fenaminom aktivatsiyu samostimulyatsii u krys. Obozrenie psikhiatrii i meditsinskoy psikhologii im. V.M. Bekhtereva. 2014;(S):202-203. (In Russ.)]

36. Якушина Н.Д., Тиссен И.Ю., Лебедев А.А., и др. Возможное участие OX1R рецепторов орексина А в компульсивном поведении и поддержании уровня тревожности после витального стресса у крыс // Вестник Смоленской государственной медицинской академии. - 2018. - Т. 17. - № 1. - С. 10-18. [Yakushina ND, Tissen IYu, Lebedev AA, et al. Probable participation of ox1r orexin a receptor in the compulsive behavior and support of the level of anxiety after vital stress in rats. Vestnik Smolenskoy gosudarstvennoy meditsinskoy akademii. 2018;17(1):10-18. (In Russ.)]

37. Abrahamson EE, Leak RK, Moore RY. The suprachiasmatic nucleus projects to posterior hypothalamic arousal systems. Neuroreport. 2001;12(2):435-440. https://doi.org/ 10.1097/00001756-200102120-00048.

38. Akiyama M, Yuasa T, Hayasaka N, et al. Reduced food anticipatory activity in genetically orexin (hypocretin) neuronablated mice. Eur J Neurosci. 2004;20(11):3054-3062. https://doi.org/ 10.1111/j.1460-9568.2004.03749.x.

39. Azizi H, Mirnajafi-Zadeh J, Rohampour K, Semnanian S. Antagonism of orexin type 1 receptors in the locus coeruleus attenuates signs of naloxone-precipitated morphine withdrawal in rats. Neurosci Lett. 2010;482(3):255-259. https://doi.org/ 10.1016/j.neulet.2010.07.050.

40. Baimel C, Borgland SL. Hypocretin modulation of drug-induced synaptic plasticity. Prog Brain Res. 2012;198:123-131. https://doi.org/10.1016/B978-0-444-59489-1.00008-2.

41. Badiani A, Belin D, Epstein D, et al. Opiate versus psychostimulant addiction: the differences do matter. Nat Rev Neurosci. 2011;12(11):685-700. https://doi.org/10.1038/nrn3104.

42. Blouin AM, Fried I, Wilson CL, et al. Human hypocretin and melanin-concentrating hormone levels are linked to emotion and social interaction. Nat Commun. 2013;4:1547. https://doi.org/10.1038/ncomms2461.

43. Borgland SL, Taha SA, Sarti F, et al. Orexin A in the VTA is critical for the induction of synaptic plasticity and behavioral 
sensitization to cocaine. Neuron. 2006;49(4):589-601. https://doi.org/10.1016/j.neuron.2006.01.016.

44. Borgland SL, Chang SJ, Bowers MS, et al. Orexin A/hypocretin-1 selectively promotes motivation for positive reinforcers. J Neurosci. 2009;29(36):11215-11225. https:// doi.org/10.1523/JNEUROSCI.6096-08.2009.

45. Boutrel B, de Lecea L. Addiction and arousal: the hypocretin connection. Physiol Behav. 2008;93(4-5):947-951. https://doi.org/10.1016/j.physbeh.2007.11.022.

46. Boutrel B, Kenny PJ, Specio SE, et al. Role for hypocretin in mediating stress-induced reinstatement of cocaine-seeking behavior. Proc Natl Acad Sci USA. 2005;102(52):19168-73. https://doi.org/10.1073/pnas.0507480102.

47. Cannella N, Economidou D, Kallupi M, et al. Persistent increase of alcohol-seeking evoked by neuropeptide S: an effectmediated by the hypothalamic hypocretin system. Neuropsychopharmacology. 2009;34(9):2125-2134. https:// doi.org/10.1038/npp.2009.37.

48. Franco R, Casado V, Cortes A, et al. G-protein-coupled receptor heteromers: function and ligand pharmacology. Br J Pharmacol. 2008;153 Suppl 1:S90-98. https://doi. org/10.1038/sj.bjp.0707571.

49. Chester JA, Cunningham CL. Baclofen Alters EthanolStimulated Activity but not Conditioned Place Preference or Taste Aversion in Mice. Pharmacol Biochem Behav.1999;63(2):325-331.https://doi.org/10.1016/s00913057(98)00253-6.

50. Chen X, Wang H, Lin Z, et al. Orexins (hypocretins) contribute to fear and avoidance in rats exposed to a single episode of footshocks. Brain Struct Funct. 2013;219(6): 2103-18. https://doi.org/10.1007/s00429-013-0626-3.

51. Chou TC, Lee CE, Lu J, et al. Orexin (Hypocretin) Neurons Contain Dynorphin. JNeurosci. 2001;21(19): RC168-RC168. https://doi.org/10.1523/JNEUROSCI.21-19-j0003.2001.

52. Cole S, Mayer HS, Petrovich GD. Orexin/Hypocretin-1 Receptor Antagonism Selectively Reduces Cue-Induced Feeding in Sated Rats and Recruits Medial Prefrontal Cortex and Thalamus. Sci Rep. 2015;5(1). https://doi. org/10.1038/srep16143.

53. Dayas CV, McGranahan TM, Martin-Fardon R, Weiss F. Stimuli Linked to Ethanol Availability Activate Hypothalamic CART and Orexin Neurons in a Reinstatement Model of Relapse. Biol Psychiatry. 2008;63(2):152-157. https:// doi.org/10.1016/j.biopsych.2007.02.002.

54. Dhaher R, Hauser SR, Getachew B, et al. The Orexin-1 Receptor Antagonist SB-334867 Reduces Alcohol Relapse Drinking, but not Alcohol-Seeking, in Alcohol-Preferring (P) Rats. J Addict Med. 2010;4(3):153-159. https:// doi.org/10.1097/ADM.0b013e3181bd893f.

55. de Lecea L. Hypocretins and the neurobiology of sleepwake mechanisms. Prog Brain Res. 2012;198:15-24. https://doi.org/10.1016/B978-0-444-59489-1.00003-3.

56. Dimitrova A, Fronczek R, Van der Ploeg J, et al. Rewardseeking behavior in human narcolepsy. J Clin Sleep Med. 2011;7(3):293-300. https://doi.org/10.5664/JCSM.1076.

57. Di Sebastiano AR, Yong-Yow S, Wagner L, et al. Orexin mediates initiation of sexual behavior in sexually naive male rats, but is not critical for sexual performance. Horm Behav. 2010;58(3): 397-404. https://doi.org/10.1016/j.yhbeh.2010.06.004.
58. Elias CF, Saper CB, Maratos-Flier E, et al. Chemically defined projections linking the mediobasal hypothalamus and the lateral hypothalamic area. J Comp Neurol. 1998;402(4):442-459. https://doi.org/10.1002/(sici)10969861(19981228)402:4<442:: aid-cne2>3.0.co;2-r.

59. Ellis J, Pediani JD, Canals $\mathrm{M}$, et al. Orexin-1 receptor-cannabinoid CB1 receptor heterodimerization results in both ligand-dependent and -independent coordinated alterations of receptor localization and function. $J$ Biol Chem. 2006;281(50):38812-38824. https://doi.org/10.1074/jbc. M602494200.

60. Espana RA, Melchior JR, Roberts DC, Jones SR. Hypocretin 1/orexin $A$ in the ventral tegmental area enhances dopamine responses to cocaine and promotes cocaine selfadministration. Psychopharmacology (Berl). 2011;214(2): 415-426. https://doi.org/10.1007/s00213-010-2048-8.

61. Estabrooke IV, McCarthy MT, Ko E, et al. Fos Expression in Orexin Neurons Varies with Behavioral State. J Neurosci. 2001;21(5):1656-1662. https://doi.org/10.1523/jneurosci.21-05-01656.2001.

62. Fadel J, Deutch AY. Anatomical substrates of orexin-dopamine interactions: lateral hypothalamic projections to the ventral tegmental area. Neuroscience. 2002;111(2): 379-387. https://doi.org/10.1016/s0306-4522(02)00017-9.

63. Fatahi Z, Assar N, Mahmoudi D, et al. Functional interaction between the orexin-1 and $\mathrm{CB} 1$ receptors within the nucleus accumbens in the conditioned place preference induced by the lateral hypothalamus stimulation. Pharmacol Biochem Behav. 2015;132:42-48. https://doi. org/10.1016/j.pbb.2015.02.023.

64. Flores A, Saravia R, Maldonado R, Berrendero F. Orexins and fear: implications for the treatment of anxiety disorders. Trends Neurosci. 2015;38(9):550-559. https://doi. org/10.1016/j.tins.2015.06.005.

65. Georgescu D, Zachariou V, Barrot M, etal. Involvement of the Lateral Hypothalamic Peptide Orexin in Morphine Dependence and Withdrawal. J Neurosci. 2003;23(8):3106-3111. https://doi.org/10.1523/jneurosci.23-08-03106.2003.

66. Godden KE, Landry JP, Slepneva N, et al. Early expression of hypocretin/orexin in the chick embryo brain. PLoS One. 2014;9(9): e106977. https://doi.org/10.1371/journal. pone.0106977.

67. Gotter AL, Roecker AJ, Hargreaves R, et al. Orexin receptors as therapeutic drug targets. Prog Brain Res. 2012;198:163-88. https://doi.org/10.1016/B978-0-444-59489-1.00010-0.

68. Grivel J, Cvetkovic V, Bayer L, et al. The wake-promoting hypocretin/orexin neurons change their response to noradrenaline after sleep deprivation. $J$ Neurosci. 2005;25(16):4127-4130. https://doi.org/10.1523/JNEUROSCI.0666-05.2005.

69. Hakansson M, de Lecea L, Sutcliffe JG, et al. Leptin receptor- and STAT3-immunoreactivities in hypocretin/orexin neurones of the lateral hypothalamus. J Neuroendocrinol. 1999;11(8):653-663. https://doi.org/10.1046/j.13652826.1999.00378.x.

70. Hara J, Beuckmann CT, Nambu T, et al. Genetic Ablation of Orexin Neurons in Mice Results in Narcolepsy, Hypophagia, and Obesity. Neuron. 2001;30(2):345-354. https://doi. org/10.1016/s0896-6273(01)00293-8. 
71. Harris GC, Wimmer M, Randall-Thompson JF, AstonJones G. Lateral hypothalamic orexin neurons are critically involved in learning to associate an environment with morphine reward. Behav Brain Res. 2007;183(1):43-51. https://doi.org/10.1016/j.bbr.2007.05.025.

72. Harris GC, Wimmer M, Aston-Jones G. A role for lateral hypothalamic orexin neurons in reward seeking. Nature. 2005;437(7058):556-559. https://doi.org/10.1038/nature04071.

73. Harris GC, Aston-Jones G. Arousal and reward: a dichotomy in orexin function. Trends Neurosci. 2006;29(10): 571-577. https://doi.org/10.1016/j.tins.2006.08.002.

74. Haynes AC, Chapman H, Taylor C, et al. Anorectic, thermogenic and anti-obesity activity of a selective orexin-1 receptor antagonist in ob/ob mice. Regul Pept. 2002;104(1-3): 153-159. https://doi.org/10.1016/s0167-0115(01)00358-5.

75. Hollander JA, Lu Q, Cameron MD, et al. Insular hypocretin transmission regulates nicotine reward. Proc Natl Acad Sci USA. 2008;105(49):19480-19485. https://doi. org/10.1073/pnas.0808023105.

76. Hutcheson DM, Quarta D, Halbout B, et al. Orexin-1 receptor antagonist SB-334867 reduces the acquisition and expression of cocaine-conditioned reinforcement and the expression of amphetamine-conditioned reward. Behav Pharmacol. 2011;22(2):173-181. https://doi. org/10.1097/FBP.0b013e328343d761.

77. Jupp B, Krivdic B, Krstew E, Lawrence AJ. The orexin(1) receptor antagonist SB-334867 dissociates the motivational properties of alcohol and sucrose in rats. Brain Res. 2011;1391: 54-59. https://doi.org/10.1016/j.brainres.2011.03.045.

78. Kadotani H, Faraco J, Mignot E. Genetic studies in the sleep disorder narcolepsy. Genome Res. 1998;8(5):427434. https://doi.org/10.1101/gr.8.5.427.

79. Kane JK, Parker SL, Li MD. Hypothalamic orexin-A binding sites are downregulated by chronic nicotine treatment in the rat. Neurosci Lett. 2001;298(1):1-4. https://doi. org/10.1016/s0304-3940(00)01730-4.

80. Kane JK, Parker SL, Matta SG, et al. Nicotine up-regulates expression of orexin and its receptors in rat brain. Endocrinology. 2000;141(10):3623-3629. https://doi. org/10.1210/endo.141.10.7707.

81. Kayaba Y, Nakamura A, Kasuya Y, et al. Attenuated defense response and low basal blood pressure in orexin knockout mice. Am J Physiol Regul Integr Comp Physiol. 2003;285(3): R581-593. https://doi.org/10.1152/ajpregu.00671.2002.

82. Koob GF. Dynamics of neuronal circuits in addiction: reward, antireward, and emotional memory. Pharmacopsychiatry. 2009;42(Suppl. 1):S32-41. https://doi. org/10.1055/s-0029-1216356.

83. Kukkonen JP, Leonard CS. Orexin/hypocretin receptor signalling cascades. $\mathrm{Br} J$ Pharmacol. 2014;171(2): 314-331. https://doi.org/10.1111/bph.12324.

84. Lawrence AJ. Regulation of alcohol-seeking by orexin (hypocretin) neurons. Brain Res. 2010;1314:124-129. https://doi.org/10.1016/j.brainres.2009.07.072.

85. Lawrence AJ, Cowen MS, Yang HJ, et al. The orexin system regulates alcohol-seeking in rats. $\mathrm{Br} J$ Pharmacol. 2006;148(6):752-759. https://doi.org/10.1038/sj.bjp. 0706789 .
86. Lebold TP, Bonaventure P, Shireman BT. Selective orexin receptor antagonists. Bioorg Med Chem Lett. 2013;23(17):4761-4769. bmcl.2013.06.057.

87. LeSage MG, Perry JL, Kotz CM, et al. Nicotine self-administration in the rat: effects of hypocretin antagonists and changes in hypocretin mRNA. Psychopharmacology (Berl). 2010;209(2):203-212. https://doi.org/10.1007/ s00213-010-1792-0.

88. LiY, Wang H, Qi K, et al. Orexins in the midline thalamus are involved in the expression of conditioned place aversion to morphine withdrawal. Physiol Behav. 2011;102(1):42-50. https://doi.org/10.1016/j.physbeh.2010.10.006.

89. Li Y, Gao X-B, Sakurai T, van den Pol AN. Hypocretin/ Orexin Excites Hypocretin Neurons via a Local Glutamate Neuron - A Potential Mechanism for Orchestrating the Hypothalamic Arousal System. Neuron. 2002;36(6):11691181. https://doi.org/10.1016/s0896-6273(02)01132-7.

90. Liu Z-W, Gao X-B. Adenosine Inhibits Activity of Hypocretin/Orexin Neurons by the A1 Receptor in the Lateral Hypothalamus: A Possible Sleep-Promoting Effect. J Neurophysiol. 2007;97(1):837-848. https://doi.org/10.1152/ jn.00873.2006.

91. Matsuki T, Nomiyama M, Takahira $\mathrm{H}$, et al. Selective loss of GABAB receptors in orexin-producing neurons results in disrupted sleep/wakefulness architecture. Proc Nat Acad Sci. 2009;106(11):4459-4464. https://doi.org/10.1073/ pnas. 0811126106.

92. Mahler SV, Smith RJ, Moorman DE, et al. Multiple roles for orexin/hypocretin in addiction. Prog Brain Res. 2012;198:79-121. https://doi.org/10.1016/b978-0-44459489-1.00007-0.

93. Mieda M, Williams SC, Sinton CM, et al. Orexin neurons function in an efferent pathway of a food-entrainable circadian oscillator in eliciting food-anticipatory activity and wakefulness. J Neurosci. 2004;24(46):10493-10501. https://doi.org/10.1523/JNEUROSCI.3171-04.2004.

94. Mignot E. Genetic and familial aspects of narcolepsy. Neurology. 1998;50(2 Suppl 1): S16-22. https://doi. org/10.1212/wnl.50.2_suppl_1.s16.

95. Mignot E, Lammers GJ, Ripley B, et al. The role of cerebrospinal fluid hypocretin measurement in the diagnosis of narcolepsy and other hypersomnias. Arch Neurol. 2002;59(10):1553-1562. https://doi.org/10.1001/archneur.59.10.1553.

96. Moorman DE, Aston-Jones G. Orexin/hypocretin modulates response of ventral tegmental dopamine neurons to prefrontal activation: diurnal influences. $J$ Neurosci. 2010;30(46):15585-15599. https://doi.org/10.1523/ JNEUROSCI.2871-10.2010.

97. Morganstern I, Chang GQ, Barson JR, et al. Differential effects of acute and chronic ethanol exposure on orexin expression in the perifornical lateral hypothalamus. Alcohol Clin Exp Res. 2010;34(5):886-896. https://doi. org/10.1111/j.1530-0277.2010.01161.x.

98. Murphy JA, Deurveilher S, Semba K. Stimulant doses of caffeine induce c-FOS activation in orexin/hypocretin-containing neurons in rat. Neuroscience. 2003;121(2):269-275. https://doi.org/10.1016/s0306-4522(03)00461-5. 
99. Nakamura A, Zhang W, Yanagisawa M, et al. Vigilance state-dependent attenuation of hypercapnic chemoreflex and exaggerated sleep apnea in orexin knockout mice. J Appl Physiol (1985). 2007;102(1):241-248. https://doi. org/10.1152/japplphysiol.00679.2006.

100. Nambu T, Sakurai T, Mizukami K, et al. Distribution of orexin neurons in the adult rat brain1Published on the World Wide Web on 17 March 1999.1. Brain Res. 1999;827(1-2): 243-260. https://doi.org/10.1016/s0006-8993(99)01336-0.

101. Naqvi NH, Rudrauf D, Damasio H, Bechara A. Damage to the insula disrupts addiction to cigarette smoking. Science. 2007;315(5811):531-534. https://doi. org/10.1126/science.1135926.

102. Narita $M$, Nagumo $Y$, Hashimoto $S$, et al. Direct involvement of orexinergic systems in the activation of the mesolimbic dopamine pathway and related behaviors induced by morphine. J Neurosci. 2006;26(2):398-405. https:// doi.org/10.1523/JNEUROSCI.2761-05.2006.

103. Park JH, Shim HM, Na AY, et al. Orexin A regulates plasma insulin and leptin levels in a time-dependent manner following a glucose load in mice. Diabetologia. 2015;58(7):1542-50. https://doi.org/10.1007/s00125-015-3573-0.

104. Pasumarthi RK, Reznikov LR, Fadel J. Activation of orexin neurons by acute nicotine. Eur J Pharmacol. 2006;535 (1-3):172-176. https://doi.org/10.1016/j.ejphar.2006. 02.021.

105. Plaza-Zabala A, Martin-Garcia E, de Lecea L, et al. Hypocretins regulate the anxiogenic-like effects of nicotine and induce reinstatement of nicotine-seeking behavior. $\mathrm{J} \mathrm{Neu}$ rosci. 2010;30(6):2300-2310. https://doi.org/10.1523/ JNEUROSCI.5724-09.2010.

106. Quarta D, Valerio E, Hutcheson DM, et al. The orexin-1 receptor antagonist SB-334867 reduces amphetamineevoked dopamine outflow in the shell of the nucleus accumbens and decreases the expression of amphetamine sensitization. Neurochem Int. 2010;56(1):11-15. https:// doi.org/10.1016/j.neuint.2009.08.012.

107. Reti IM, Reddy R, Worley PF, Baraban JM. Selective expression of Narp, a secreted neuronal pentraxin, in orexin neurons. J Neurochem. 2002;82(6):1561-1565. https:// doi.org/10.1046/j.1471-4159.2002.01141.x.

108. Richardson KA, Aston-Jones G. Lateral hypothalamic orexin/hypocretin neurons that project to ventral tegmental area are differentially activated with morphine preference. J Neurosci. 2012;32(11):3809-3817. https://doi. org/10.1523/JNEUROSCI.3917-11.2012.

109. Risold PY, Griffond B, Kilduff TS, et al. Preprohypocretin (orexin) and prolactin-like immunoreactivity are coexpressed by neurons of the rat lateral hypothalamic area. Neurosci Lett. 1999;259(3):153-156. https://doi. org/10.1016/s0304-3940(98)00906-9.

110. Rosin DL, Weston MC, Sevigny CP, et al. Hypothalamic orexin (hypocretin) neurons express vesicular glutamate transporters VGLUT1 or VGLUT2. J Comp Neurol. 2003;465(4): 593-603. https://doi.org/10.1002/cne.10860.

111. Sakurai T, Nagata R, Yamanaka A, et al. Input of orexin/ hypocretin neurons revealed by a genetically encoded tracer in mice. Neuron. 2005;46(2):297-308. https://doi. org/10.1016/j.neuron.2005.03.010.
112. Sakurai T. Reverse pharmacology of orexin: from an orphan GPCR to integrative physiology. RegulPept. 2005;126(1-2): 3-10. https://doi.org/10.1016/j.regpep.2004.08.006.

113. Sartor GC, Aston-Jones GS. A septal-hypothalamic pathway drives orexin neurons, which is necessary for conditioned cocaine preference. J Neurosci. 2012;32(13):4623-4631. https://doi.org/10.1523/JNEUROSCI.4561-11.2012.

114. Scammell TE. Narcolepsy. N Engl J Med. 2015;373(27): 2654-2662. https://doi.org/10.1056/NEJMra1500587

115. Shabanov PD, Lebedev AA, Droblenkov AV, et al. Delayed behavioral and morphological subsequences of activation of the stress-antistress system in early ontogeny in rats. Int J Neuropsychopharmacol. 2009;72(6):7-14.

116. Sharf R, Sarhan M, Brayton CE, et al. Orexin signaling via the orexin 1 receptor mediates operant responding for food reinforcement. Biol Psychiatry. 2010;67(8):753-760. https://doi.org/10.1016/j.biopsych.2009.12.035.

117. Schmitt O, Usunoff KG, Lazarov NE, et al. Orexinergic innervation of the extended amygdala and basal ganglia in the rat. Brain Struct Funct. 2012;217(2):233-256. https:// doi.org/10.1007/s00429-011-0343-8.

118. Schneider ER, Rada P, Darby RD, et al. Orexigenic peptides and alcohol intake: differential effects of orexin, galanin, and ghrelin. Alcohol Clin Exp Res. 2007;31(11):1858-1865. https://doi.org/10.1111/j.1530-0277.2007.00510.x.

119. Shoblock JR, Welty N, Aluisio L, et al. Selective blockade of the orexin-2 receptor attenuates ethanol self-administration, place preference, and reinstatement. Psychopharmacology (Berl). 2011;215(1):191-203. https://doi. org/10.1007/s00213-010-2127-x.

120. Schone C, Apergis-Schoute J, Sakurai T, et al. Coreleased orexin and glutamate evoke nonredundant spike outputs and computations in histamine neurons. Cell Rep. 2014;7(3): 697-704. https://doi.org/10.1016/j.celrep.2014.03.055.

121. Steiner MA, Lecourt $H$, Jenck $F$. The brain orexin system and almorexant in fear-conditioned startle reactions in the rat. Psychopharmacology (Berl). 2012;223(4):465-475. https://doi.org/10.1007/s00213-012-2736-7.

122. Sundvik M, Panula P. Interactions of the orexin/hypocretin neurones and the histaminergic system. Acta Physiol(Oxf). 2015;213(2):321-333. https://doi.org/10.1111/ apha.12432.

123. Tang J, Chen J, Ramanjaneya M, et al. The signalling profile of recombinant human orexin-2 receptor. Cell Signal. 2008;20(9):1651-1661. https://doi.org/10.1016/j.cellsig.2008.05.010.

124. Tissen I, Vinogradov PM, Khokhlov PP, et al. P1.g.061 Orexin receptor type $1(\mathrm{Ox} 1 \mathrm{R})$ are involved in the formation and reinstatement of conditioned place preference. Eur Neuropsychopharmacol. 2015;25: S269-S270. https:// doi.org/10.1016/s0924-977x(15)30313-8.

125. Tsunematsu T, Fu LY, Yamanaka A, et al. Vasopressin increases locomotion through a $\mathrm{V} 1 \mathrm{a}$ receptor in orexin/ hypocretin neurons: implications for water homeostasis. J Neurosci. 2008;28(1):228-238. https://doi. org/10.1523/JNEUROSCI.3490-07.2008.

126. Velley L. The role of intrinsic neurons in lateral hypothalamic self-stimulation. Behav Brain Res. 1986;22(2): 141-152. https://doi.org/10.1016/0166-4328(86)90035-5. 
127. von der Goltz C, Koopmann A, Dinter C, et al. Orexin and leptin are associated with nicotine craving: a link between smoking, appetite and reward. Psychoneuroendocrinology. 2010;35(4):570-577. https://doi.org/10.1016/j.psyneuen. 2009.09.005.

128. von der Goltz C, Koopmann A, Dinter C, et al. Involvement of orexin in the regulation of stress, depression and reward in alcohol dependence. Horm Behav. 2011;60(5): 644-650. https://doi.org/10.1016/j.yhbeh.2011.08.017.

129. Voorhees $\mathrm{CM}$, Cunningham $\mathrm{CL}$. Involvement of the orexin/ hypocretin system in ethanol conditioned place preference. Psychopharmacology (Berl). 2011;214(4):805-818. https://doi.org/10.1007/s00213-010-2082-6.

130. Wang $C$, Pan $Y$, Zhang $R$, et al. Heterodimerization of mouse orexin type 2 receptor variants and the effects on signal transduction. Biochim Biophys Acta. 2014;1843(3):652-63. https://doi.org/10.1016/j.bbamcr.2013.12.010.

131. Wang Z, Faith M, Patterson F, et al. Neural substrates of abstinence-induced cigarette cravings in chronic smokers. J Neurosci. 2007;27(51):14035-14040. https://doi. org/10.1523/JNEUROSCI.2966-07.2007.

132. Williams $R H$, Jensen $L T$, Verkhratsky $A$, et al. Control of hypothalamic orexin neurons by acid and $\mathrm{CO}_{2}$. Proc Natl Acad Sci USA. 2007;104(25):10685-10690. https://doi. org/10.1073/pnas.0702676104.

133. Yamanaka A, Beuckmann CT, Willie JT, et al. Hypothalamic Orexin Neurons Regulate Arousal According to Energy Balance in Mice. Neuron. 2003;38(5):701-713. https:// doi.org/10.1016/s0896-6273(03)00331-3.

134. Yamanaka A, Muraki Y, Ichiki K, et al. Orexin neurons are directly and indirectly regulated by catecholamines in a complex manner. J Neurophysiol. 2006;96(1):284-298. https://doi.org/10.1152/jn.01361.2005.

135. Yoshida K, McCormack S, Espana RA, et al. Afferents to the orexin neurons of the rat brain. J Comp Neurol. 2006;494(5):845-861. https://doi.org/10.1002/cne. 20859.

136. Xie X, Crowder TL, Yamanaka A, et al. GABA(B) receptormediated modulation of hypocretin/orexin neurones in mouse hypothalamus. J Physiol. 2006;574(Pt 2):399-414. https://doi.org/10.1113/jphysiol.2006.108266.

137. Zhang GC, Mao LM, Liu XY, Wang JQ. Long-lasting upregulation of orexin receptor type 2 protein levels in the rat nucleus accumbens after chronic cocaine administration. J Neurochem. 2007;103(1):400-407. https://doi. org/10.1111/j.1471-4159.2007.04748.x.

138. Zhou Y, Bendor J, Hofmann L, et al. Mu opioid receptor and orexin/hypocretin mRNA levels in the lateral hypothalamus and striatum are enhanced by morphine withdrawal. J Endocrinol. 2006;191(1):137-45. https://doi.org/10.1677/joe.1.06960.

139. Zhou Y, Cui CL, Schlussman SD, et al. Effects of cocaine place conditioning, chronic escalating-dose «binge» pattern cocaine administration and acute withdrawal on orexin/hypocretin and preprodynorphin gene expressions in lateral hypothalamus of Fischer and Sprague-Dawley rats. Neuroscience. 2008;153(4):1225-1234. https://doi. org/10.1016/j.neuroscience.2008.03.023.

140. Zhu Y, Miwa Y, Yamanaka A, et al. Orexin receptor type-1 couples exclusively to pertussis toxin-insensitive G-proteins, while orexin receptor type-2 couples to both pertussis toxin-sensitive and -insensitive G-proteins. J Pharmacol Sci. 2003;92(3):259-266. https://doi.org/10.1254/jphs.92.259.
- Информация об авторах

Илья Юрьевич Тиссен - канд. биол. наук, старший научный сотрудник отдела нейрофармакологии им. С.В. Аничкова. ФГБНУ «Институт экспериментальной медицины», СанктПетербург. E-mail: iljatis@mail.ru.

Андрей Андреевич Лебедев - д-р биол. наук, профессор, заведующий лабораторией общей фармакологии отдела нейрофармакологии им. С.В. Аничкова. ФГБНУ «Институт экспериментальной медицины», Санкт-Петербург. E-mail: aalebedev-iem@rambler.ru.

Евгений Рудольфович Бычков - канд. мед. наук, заведующий лабораторией химии и фармакологии лекарственных средств отдела нейрофармакологии им. С.В. Аничкова. ФГБНУ «Институт экспериментальной медицины», Санкт-Петербург. E-mail: bychkov@mail.ru.

Никанор Васильевич Лавров - канд. мед. наук, доцент кафедры фармакологии. ФГБОУ ВО «Санкт-Петербургский государственный педиатрический медицинский университет» Минздрава РФ, Санкт-Петербург. E-mail: nikanlavr@rambler.ru.

Виталий Иванович Морозов - канд. мед. наук, докторант отдела нейрофармакологии им. С.В. Аничкова. ФГБНУ «Институт экспериментальной медицины», Санкт-Петербург. E-mail: vitmoroz@yandex.ru.

Петр Дмитриевич Шабанов - д-р мед. наук, профессор, заведующий отделом нейрофармакологии им. С.В. Аничкова, ФГБНУ «Институт экспериментальной медицины», СанктПетербург; заведующий кафедрой фармакологии, ФГБВОУ ВО «Военно-медицинская академия им. С.М. Кирова» МО РФ, Санкт-Петербург. E-mail: pdshabanov@mail.ru.
- Information about the authors

Ilja Yu. Tissen - PhD (Pharmacology), Senior researcher, Dept. of Neuropharmacology. Institute of Experimental Medicine, Saint Petersburg, Russia.E-mail: iljatis@mail.ru.

Andrei A. Lebedev - Dr. Biol. Sci. (Pharmacology), Head of the Laboratory of General Pharmacology, Dept. of Neuropharmacology. Institute of Experimental Medicine, Saint Petersburg, Russia. E-mail: aalebedev-iem@rambler.ru.

Eugenii R. Bychkov - PhD (Pathophysiology), Head of the Laboratory of Chemistry and Pharmacology of Medicinal Compounds, Dept. of Neuropharmacology. Institute of Experimental Medicine, Saint Petersburg. Russia. E-mail: bychkov@mail.ru.

Nikanor V. Lavrov - PhD (Pharmacology), Assistant Professor, Dept. of Pharmacology. St. Petersburg State Paediatric Medical University, Saint Petersburg, Russia. E-mail: nikanlavr@rambler.ru.

Vitalii I. Morozov - PhD (Narcology), Postdoc Student, Dept. of Neuropharmacology. Institute of Experimental Medicine, Saint Petersburg. Russia. E-mail: vitmoroz@yandex.ru.

Petr D. Shabanov - Dr. Med. Sci. (Pharmacology), Professor and Head, Dept. of Neuropharmacology, Institute of Experimental Medicine, Saint Petersburg, Russia; Head, Department of Pharmacology, S.M. Kirov Military Medical Academy, Saint Petersburg, Russia.E-mail: pdshabanov@mail.ru. 